\title{
The future of virtual colonography
}

\author{
Helen Fenlon MD, Paul C Adams MD
}

$\mathrm{D}_{\mathrm{s}}^{\mathrm{r}}$ Helen Fenlon is a Consultant Radiologist at the Mater Misericordiae University Hospital, Dublin, Ireland. Before taking up the position as Consultant Radiologist in 1999, Dr Fenlon was a Fellow in Body Imaging at Boston Medical Center, Boston University Hospital (Boston, Massachusetts), from 1996 to 1998, and a Staff Radiologist (Assistant Professor of Radiology) at the same centre from 1998 to 1999. Dr Fenlon first became involved in research into computed tomography (CT) colonography (virtual colonoscopy) in 1996 while working with Professor Joseph T Ferrucci at the Boston Medical Center. Since that time, she has published many papers on the topic of CT colonography, including a landmark paper in The New England Journal of Medicine comparing CT colonography with conventional colonoscopy in 1999 (1). She is currently involved in a multiinstitutional investigation of the use of computerassisted diagnosis for interpretation of CT colonography studies, which is a collaboration between the Vision Systems Laboratory at Dublin City University, Dublin, Ireland, and the Departments of Radiology and Gastroenterology at the Mater Misericordiae University Hospital.

PA: Can you outline your interests in the area of CT colonography?

HF: I began my research into CT colonography while working with Professor Joseph T Ferrucci as a Fellow in Body Imaging at the Boston Medical Center, Boston University Hospital, in 1996. Our initial research was funded by a Radiological Society of North America Research and Education Fellow Award from 1997 to 1999. We initially studied a comparison of CT colonography and convention colonoscopy in 100 patients at increased risk for colorectal cancer. This work was published in The New England Journal of Medicine in 1999 (1). The results of this study showed that CT colonography provides a total colon examination in the majority of patients and has a similar performance to conventional colonoscopy for colorectal cancer detection. Its sensitivity for large polyps (greater than $1 \mathrm{~cm}$ in size) was $91 \%, 83 \%$ for medium-sized polyps ( $5 \mathrm{~mm}$ to $9 \mathrm{~mm}$ ) and $55 \%$ for diminutive polyps (less than $5 \mathrm{~mm}$ in size). Following on from that work, we published a number of papers on a variety of aspects of CT colonography. These included the use of CT colonography to evaluate the bowel proximal obstructing cancers (2), the effect of intravenous smooth muscle relaxants on CT colonography (3), a comparison of two-dimensional (2D) versus three-dimensional interpretations of CT colonography studies (4) and the use of computer-assisted diagnosis for interpretation of CT colonography $(5,6)$ (Figures 1 and 2).
I am currently a member of the Working Group on Virtual Colonoscopy, which comprises a group of North American and European radiologists with an interest in CT colonography research, development and implementation. This group has published a number of papers providing guidelines for performance of CT colonography studies, and mechanisms for reporting and follow-up of abnormal cases (7). I am also actively involved in CT colonography training through the European Society for Gastrointestinal and Abdominal Radiology training workshops.

PA: Although CT colonography has been performed in Canada, it has not yet been widely implemented, perhaps because of the lack of professional fees. Can you describe how the procedure has been implemented in Ireland? HF: CT colonography is currently only performed in selected centres in Ireland. More widespread use of CT colonography in Ireland is limited for a variety of reasons:

- Lack of appropriately trained radiologists;

- Lack of private health insurance reimbursement; and

- Limited access to CT scanners because of competing clinical workload.

However, despite these difficulties, the general public, primary care physicians and gastroenterologists are very enthusiastic about CT colonography. Indeed, many patients would prefer to pay for this test rather than undergo other, fully reimbursed colorectal cancer screening tests. We have performed in excess of 900 CT colonography examinations over the past five years at our institution, where there is access to both private and public multislice CT scanners. The studies that we have performed to date include both clinical and research cases. With regard to clinical cases, demand for CT colonography in our institution for symptomatic patients has increased considerably over the past five years. Patients referred for CT colonography include those immediately following a failed colonoscopy, patients who have had a previous difficult colonoscopy, frail and elderly patients, patients with prosthetic valves and patients who refuse all other colon tests. CT colonography is performed on a limited basis for screening. According to the guidelines of the Working Group on Virtual Colonoscopy we do not accept self-referrals for CT colonography. On the contrary, we actively involve the primary care physicians and the gastroenterologists at our institution in both patient referral 

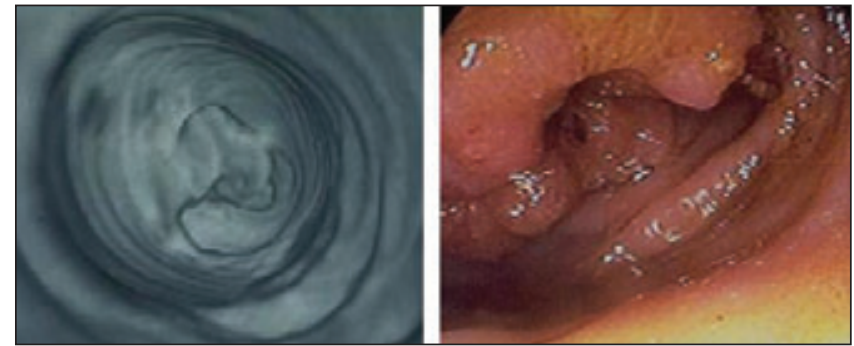

Figure 1) Three-dimensional computed tomography colonography view of a splenic flexure carcinoma (Left). Same tumour seen at endoscopy (Right)

and follow-up. We have developed a close working relationship with the gastroenterologists in our hospital who welcome this as a new and promising technique.

With increasing availability of multislice CT scanners, greater numbers of radiologists who have the required skills for CT colonography interpretation and a gradual acceptance of the technique by private health insurers, it is likely that the number of CT colonography examinations performed in this country will dramatically increase over the next few years.

PA: When the procedure was first described, it seemed like something out of a Star Wars movie. Now, I am more frequently seeing examples of $2 \mathrm{D}$ static images that resemble air contrast barium enema pictures. Can you comment on where this will likely end up? The duration of the examination and the duration of reading the examination seem critical.

HF: Since CT colonography was first described in 1994 (8), a variety of different techniques for CT colonography interpretation have been described. These included primary threedimensional reading with studies resembling an endoscopic fly-through of the colon, primary axial $2 \mathrm{D}$ viewing similar to conventional CT interpretation and 2D viewing with multiplanar reconstructions for problem solving. It appears that the level of radiologists' experience and training is a more important factor in terms of the sensitivity of the technique than the specific mode in which the study is read. Software for CT colonography interpretation is now a standard feature of many CT reading stations, and is faster and significantly more userfriendly than what was available in the early days. An average CT colonography study can now be read in the order of $5 \mathrm{~min}$ to $10 \mathrm{~min}$ compared with reading times in excess of $30 \mathrm{~min}$ 10 years ago. For the patient, the study takes approximately $10 \mathrm{~min}$, and this includes time for insertion of the rectal tube and scanning in both supine and prone positions. The net effect has been that over the past decade, CT colonography has become a much more acceptable test for both patients and radiologists.

PA: Can you outline the advances in fecal tagging that may alleviate the need for a cleansing preparation?

HF: It is well known that the most unattractive aspect of any colon test for patients is the bowel preparation. We routinely use a barium enema preparation (Fleet enema, Johnson \& Johnson/Merck Consumer Pharmaceuticals of Canada). This seems preferable to the high volume preparations sometimes used for colonoscopy (GoLytely, Braintree Laboratories Inc, USA). We find that patients tolerate the barium enema-type preparations better than the higher volume colonoscopy preparations, and that they result in a drier mucosal surface that is more appropriate for CT colonography.

Significant advances have been made in the design and formulation of high-density bowel preparations with a minimum

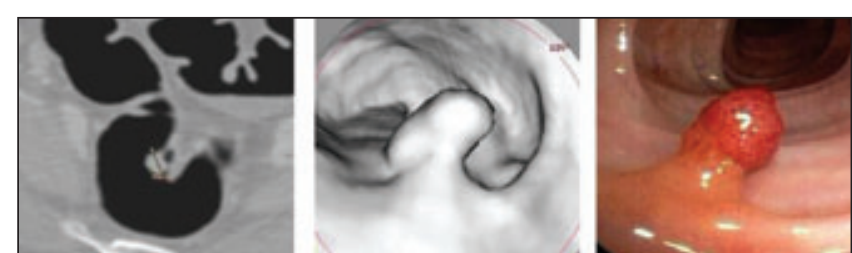

Figure 2) Seven-millimetre polyp seen on axial two-dimensional computed tomography colonography (Left), three-dimensional computed tomography colonography (Middle) and at conventional colonoscopy (Right)

laxative component for CT colonography, the so called 'fecaltagging' agents. These preparations require the patient to take an oral contrast drink, usually dilute barium, for $48 \mathrm{~h}$ to $72 \mathrm{~h}$ before the procedure. Because many of these preparations have only a minimum laxative component, they are more acceptable to patients than standard cathartic preparations. Patients can go about their daily activities while taking the preparation with little associated disruption or discomfort. Fecal-tagging agents insure that any residual material within the colon is of higher density than the colonic wall and pathology such as polyps and cancers, which stand out in contrast as negative filling defects. Furthermore, software has been developed that allows the higher density intraluminal material to be removed electronically, so-called 'electronic cleansing'. Preliminary published results $(9,10)$ suggest that fecal-tagging agents work well with sensitivities and specificities similar to those found in the fully prepared colon.

PA: How has the procedure been welcomed by gastroenterologists in Ireland?

HF: Most gastroenterologists in Ireland welcome the development of CT colonography and its wider implementation. Our gastroenterologists are currently overwhelmed by the volume of patients coming for colonoscopy, and welcome a test that reduces the number of negative colonoscopies required and increases the demand for therapeutic colonoscopy. In particular, gastroenterologists recognize that CT colonography is a useful test in selected patients, particularly those who have had a failed colonoscopy or a previously difficult colonoscopy, or patients with obstructing cancers. Many of our colorectal surgeons now request CT colonography before surgery in patients with colorectal cancer in whom the proximal colon cannot be adequately visualized due to the presence of a distal occlusive tumour.

PA: Do you forsee ambulatory clinics that could offer CT colonography and colonoscopy at the same site?

HF: As with any potential screening test, it will be necessary to carefully examine the performance of CT colonography in average-risk persons when performed at a community level. Although it is clear that CT colonography provides results comparable to colonoscopy when carried out in selected academic centres where adequate training and experience exists, we do not know how well the technique will perform when more widely applied in the general community. Sufficient numbers of trained radiologists will be required. Issues of cost and reimbursement will have to be adequately addressed. CT colonography will have to be provided at a cost lower than currently exists to be a feasible screening test because it is a diagnosis-only test with a proportion of patients (one in 12 average-risk patients) requiring follow-up colonoscopy. Standard imaging protocols will need to be agreed on and careful mechanisms for follow-up of all abnormal results will 
be required. As with mammography, issues of quality assurance and accreditation will need to be addressed. Many of these issues are currently being addressed by the Working Group on Virtual Colonoscopy in conjunction with relevant professional bodies.

If CT colonography can overcome these hurdles (and I believe it will) and if it is recognized as a valid screening test by government health agencies and private health insurers, then it is likely that centres with close radiology/gastroenterology links will develop, offering both CT colonography and conventional colonoscopy on the same site. This is currently the practice in a number of American centres where a proven track record for CT colonography performance exists and where issues of reimbursement have been tackled.

PA: There has been concern about radiation exposure. Will this method eventually move to the magnetic resonance imaging (MRI) platform?

HF: In the early days of CT colonography, the average radiation exposure per patient was in the order of $6 \mathrm{mSv}$ to $8 \mathrm{mSv}$. However, a considerable amount of work has been published on low-dose and ultralow-dose CT colonography in which tube outputs as low as $15 \mathrm{mAs}$ to $20 \mathrm{mAs}$ have been used. The patient radiation dose has been cut significantly to the order of $2 \mathrm{mSv}$ per study. This is significantly and consistently lower than for barium enemas. While, from a radiation exposure point of view, MRI would appear to be an attractive modality for performing screening colonography studies, the promising results from a small number of research studies $(11,12)$ have not been replicated outside of a handful of specialist academic MR centres. Difficulties with MR colonography include image artefacts at the air-soft tissue interface, artefacts from respiration and peristalsis, the need for bowel filling with dilute gadolinium, lower spatial resolution compared with CT, as well as limited access to MR scanners. I do not see MRI replacing CT for colonography anytime soon.

PA: Is this an easier screening test for colon cancer than colonoscopy?

HF: A major plus in CT colonography is that it is well tolerated by patients. The test requires no sedation; therefore, there is no recovery time and patients are free to leave the department once the examination is over. Patients' acceptance of this technique will also increase with the more widespread use of fecal-tagging agents. Furthermore, the risk profile of CT colonography is extremely encouraging. In a review of over 20,000 CT colonography examinations, there was only one report of a significant complication, and that was a bowel perforation in a patient with obstructing colon cancer. This patient was symptomatic before coming to the CT suite, and it is likely that the preparation, rather than the procedure, resulted in the complication.

PA: Can you comment on the costs and fees for CT colonography versus colonoscopy?

HF: A number of papers have been published regarding costs and fees for CT colonography $(13,14)$. The results of these studies are somewhat at variance with each other. The most recent publication in the Canadian Medical Association Journal (7) suggests that CT colonography will not be a feasible screening test if offered at the current fees. As stated previously, it is clear that CT colonography will have to be a much cheaper test than colonoscopy, comparable in cost to barium enema, because a definite percentage of all patients (approximately one in 12) will require a colonoscopy to investigate positive CT colonography findings.

PA: In closing, can you predict the future of the procedure?

HF: In our institution, CT colonography has now replaced the barium enema as the test of choice in all symptomatic patients. The ability to provide CT colonography will significantly increase with ready access to multislice CT scanners, all of which are now equipped the appropriate workstations for CT colonography interpretation. As exposure to CT colonography increases in the radiology community and training courses for CT colonography interpretation are more widely available, it is likely that radiologists will acquire the necessary skills to read these studies. The consensus of the Working Group on Virtual Colonoscopy is that CT colonography can now be performed at selected centres for screening for colorectal cancer where there is a proven track record and where a proper mechanism for follow-up of abnormal patients exists. If the currently achievable results in these centres can be more widely applied, then CT colonography may become an important screening test for colorectal cancer. This remains somewhat in the future, however, because issues of cost, reimbursement and approval from government health care bodies remain.

\section{REFERENCES}

1. Fenlon HM, Nunes DP, Schroy PC 3rd, Barish MA, Clarke PD, Ferrucci JT. A comparison of virtual and conventional colonoscopy for the detection of colorectal polyps. N Engl J Med 1999;341:1496-503. (Erratum in 2000;342:524).

2. Fenlon HM, McAneny DB, Nunes DP, Clarke PD, Ferrucci JT. Occlusive colon carcinoma: Virtual colonoscopy in the preoperative evaluation of the proximal colon. Radiology 1999;210:423-8.

3. Bruzzi JF, Moss AC, Brennan DD, MacMathuna P, Fenlon HM. Efficacy of IV Buscopan as a muscle relaxant in CT colonography. Eur Radiol 2003;13:2264-70. (Erratum in 2004;14:756).

4. Bruzzi JF, Moss AC, Brennan DD, MacMathuna P, Fenlon HM. Colonic surveillance by CT colonography using axial images only. Eur Radiol 2004;14:763-7.

5. Zalis ME, Barish MA, Choi JR, et al; Working Group on Virtual Colonoscopy. CT colonography reporting and data system: A consensus proposal. Radiology 2005;236:3-9.

6. Ferrucci J, Barish M, Choi R, et al; Working Group on Virtual Colonoscopy. Virtual colonoscopy. JAMA 2004;292:431-2.

7. Heitman SJ, Manns BJ, Hilsden RJ, Fong A, Dean S, Romagnuolo J. Cost-effectiveness of computerized tomographic colonography versus colonoscopy for colorectal cancer screening. CMAJ 2005;173:877-81.

8. Vining DJ, Gelfand DW, Bechtold RE, Scharling ES, Grishaw EK, Shifrin RY Technical feasibility of colon imaging with helical CT and virtual reality. Am J Roentgenol 1994;162:S104

9. Lefere P, Gryspeerdt S, Marrannes J, Baekelandt M, Van Holsbeeck B. CT colonography after fecal tagging with a reduced cathartic cleansing and a reduced volume of barium. AJR Am J Roentgenol 2005;184:1836-42.

10. Iannaccone R, Laghi A, Catalano C, et al. Computed tomographic colonography without cathartic preparation for the detection of colorectal polyps. Gastroenterology 2004;127:1300-11.

11. Ajaj W, Lauenstein TC, Pelster G, et al. MR colonography in patients with incomplete conventional colonoscopy. Radiology 2005;234:452-9.

12. Ajaj W, Pelster G, Treichel U, et al. Dark lumen magnetic resonance colonography: Comparison with conventionalcolonoscopy for the detection of colorectal pathology. Gut 2003;52:1738-43.

13. Ladabaum U, Song K, Fendrick AM. Colorectal neoplasia screening with virtual colonoscopy: When, at what cost, and with what national impact? Clin Gastroenterol Hepatol 2004;2:554-63.

14. Sonnenberg A, Delco F, Bauerfeind P. Is virtual colonoscopy a costeffective option to screen for colorectal cancer? Am J Gastroenterol 1999;94:2268-74 


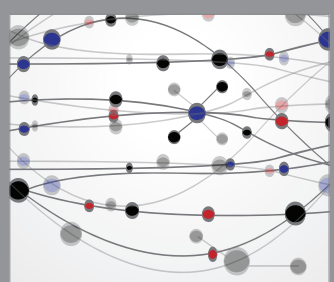

The Scientific World Journal
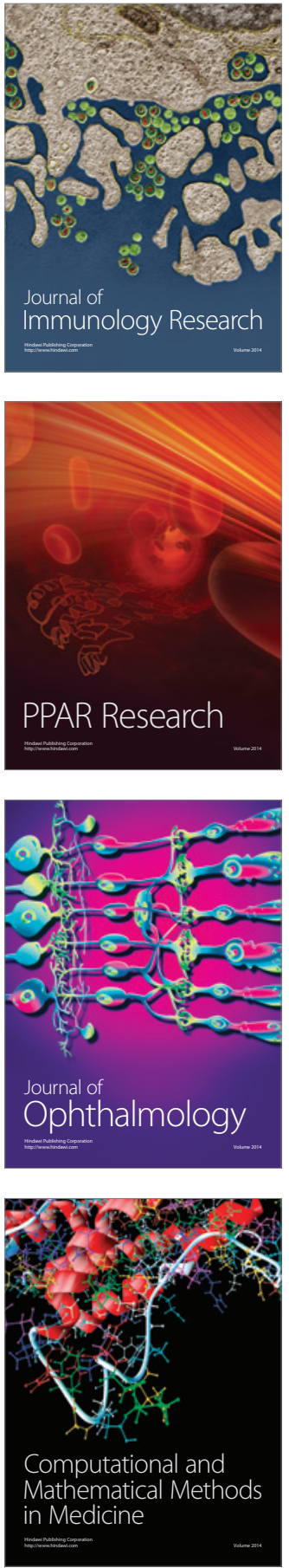

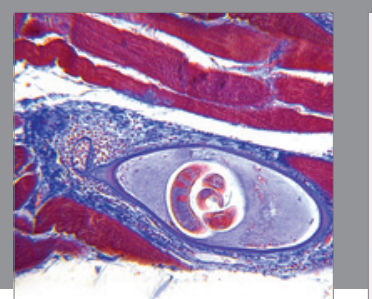

Gastroenterology Research and Practice

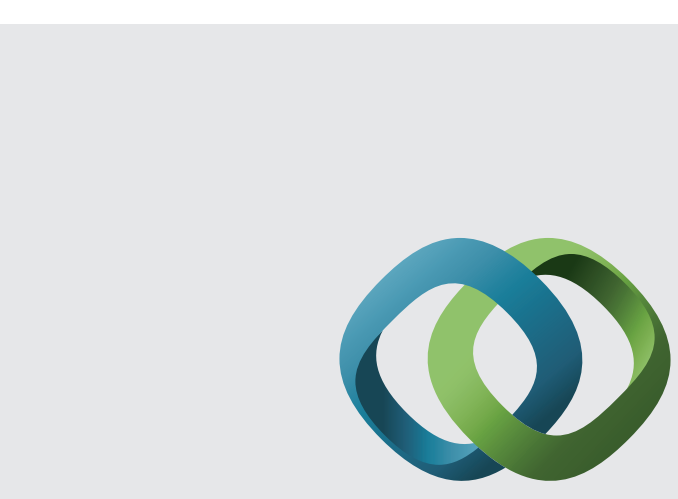

\section{Hindawi}

Submit your manuscripts at

http://www.hindawi.com
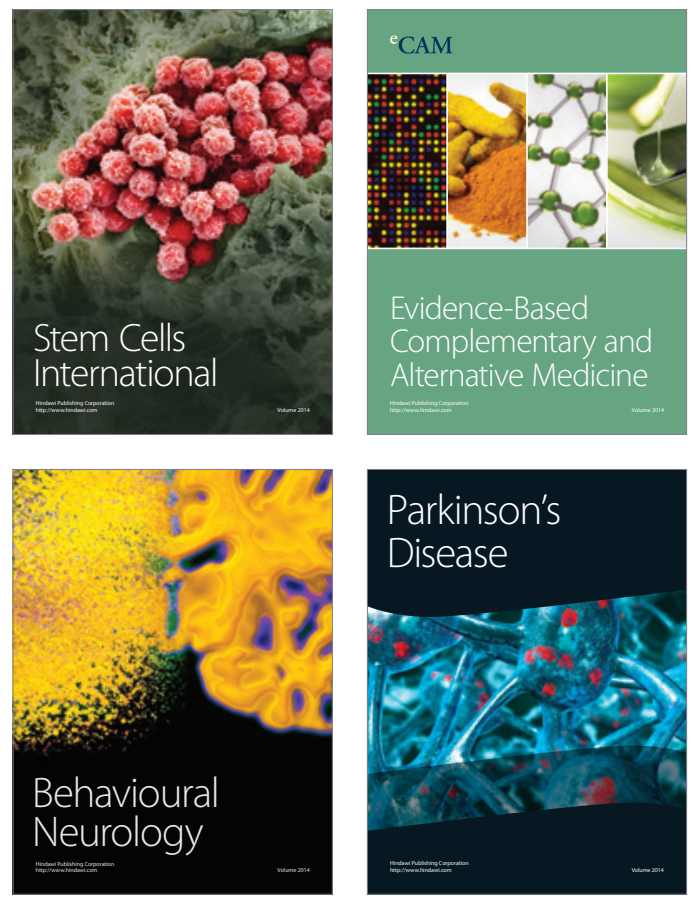
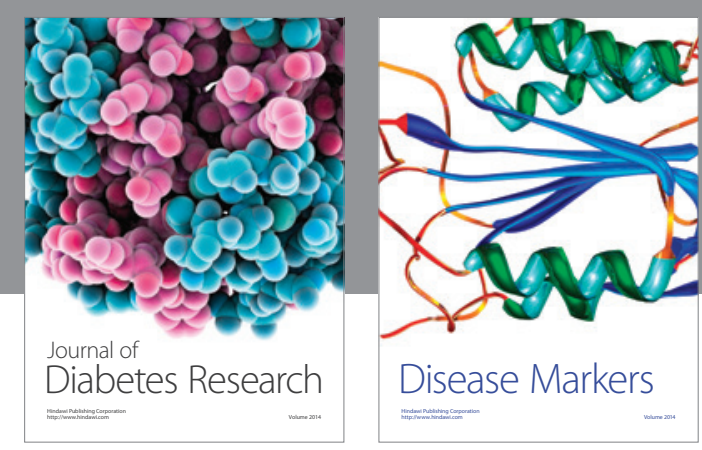

Disease Markers
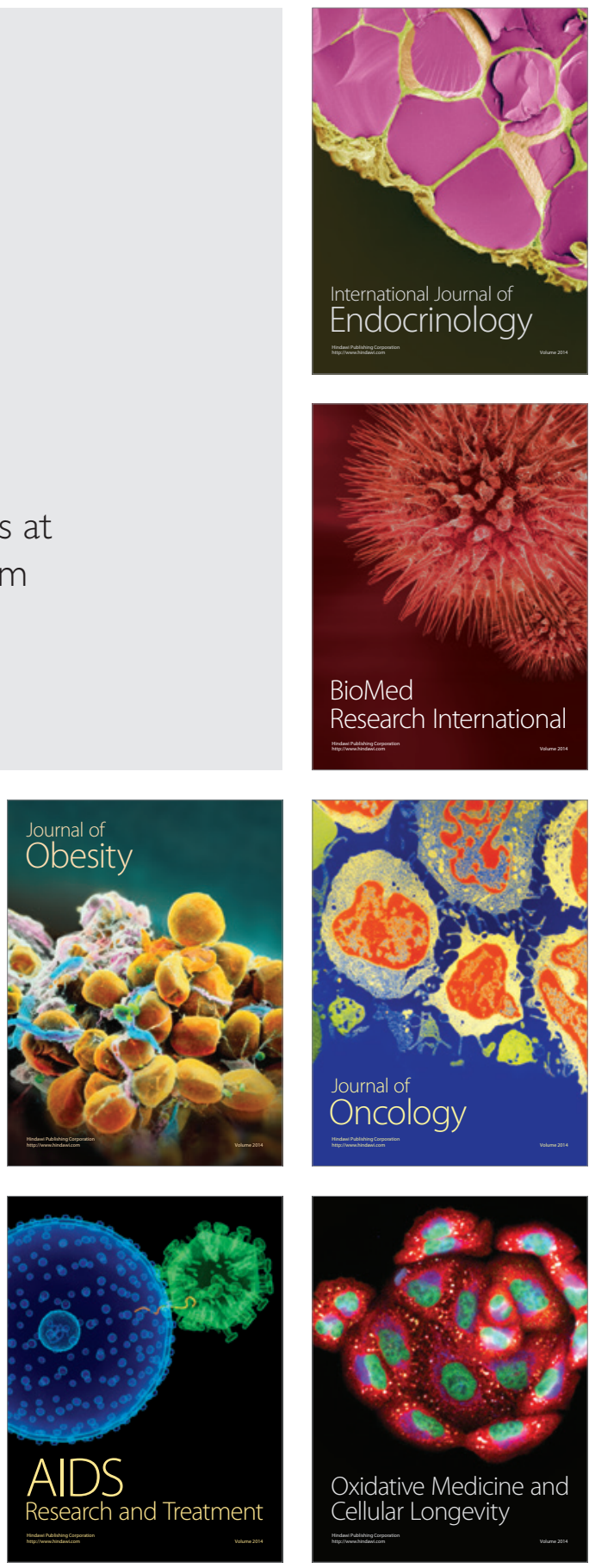